\title{
METODOLOGÍA REALISTA- CRÍTICA Y ÉTICA DEL RAZONAMIENTO JUDICIAL* (Realismo jurídico como alternativa práctica al discurso normativista de los jueces)
}

\author{
Enrique P. Haba \\ Universidad de Costa Rica
}

The question is not whether we shall adopt free legal decision, but whether we shall admit that we already have it.

Frank

El ser un buen pensador es más difícil de lo que a primera vista parece, porque no sólo hay que defenderse de las soluciones: hay que defenderse hasta de las cuestiones, de los mismos problemas de los enunciados.

Vaz Ferreira

\section{Generalidades}

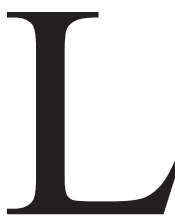

a Teoría del Derecho, tomando tal expresión para hacer referencia a exámenes como los que se publican en esta Revista ${ }^{1}$, indaga señaladamente dos órdenes de cuestiones. 1) Ella se esfuerza por sacar a luz descriptivamente ciertas estructuras de razonamiento que, según tales o cuales autores, suelen estar presentes ya en los discursos de los juristas profesionales, aun cuando estos mismos no posean una conciencia suficientemente clara al respecto. 2) Y además enjuicia dichas formas de razonar, ya sea para justificarlas o para impugnarlas, en mayor o menor medida, con base en unos u otros modelos básicos de razonamiento que esos autores consideran, por las razones que

(*) Desde hace unos cuantos años vengo anunciando que está por aparecer mi libro: Metodología (realista) del Derecho Sin embargo, distintas circunstancias han hecho que no salga a luz y no sé si finalmente llegaré a verlo publicado; por eso escojo, para darlos a conocer aquí, unos pasajes de los materiales preparados para dicha obra. [Algunas partes de esos materiales (pero no lo presentado aquí), junto con otros no destinados a dicha obra, están en mi libro $\mathrm{El}$ espejismo de la interpretación literal, programado para el año próximo.]

${ }^{1}$ Vale decir, el género de estudios que cabría denominar, de manera más específica, "Investigación sobre las Bases del Derecho" (Rechtsgrundlagenforschung), esto es: no son las teorías corrientes - doctrina o dogmática jurídicas- que usan los juristas para su actividad profesional (abogados, jueces, etc.), sino la meta-teoría donde se reflexiona sobre la naturaleza de aquellas y sobre características del pensamiento jurídico en general. 
fuere (sobre las cuales discuten mucho entre sí), los más adecuados para llevar adelante las tareas intelectuales propias del jurista. Ambos extremos están muy interrelacionados, pero no son la misma cosa. Al capítulo (1), digamos la ePISTEMOLogía del Derecho, el otro (2) le agrega una propuesta. Este último no se limita a describir cosas que los juristas hacen (supuestamente) en sus discursos, sino que pretende ofrecerles una METODOLOGíA: ya sea para que ellos prosigan razonando básicamente de la misma manera que antes (detalles más, detalles menos), o bien, para que procedan a modificar aspectos fundamentales de sus hábitos discursivos.

Los dos ítems no suelen aparecer diferenciados netamente entre sí en esos estudios. Sin embargo, considero fundamental no perder de vista la distinción, pues ambos no se acreditan en función de exactamente el mismo tipo de exigencias. El acierto de lo que se exponga en (1) no depende de que lo ahí sacado a luz vaya a ser conocido o no por los propios protagonistas corrientes de la actividad jurídica profesional; a fortiori no puede quedar subordinado a la circunstancia de si ese conocimiento sea aceptado o no como tal por parte de ellos mismos. Recuérdese que la Teoría del Derecho, en cuanto disciplina intelectual específica, procura sacar a luz más bien lo que son estructuras subyacentes de los discursos del derecho, a diferencia de la doctrina común de los juristas. El ítem (2), en cambio, da toda la impresión de responder a la esperanza de influir sobre las maneras como plantean las cosas los propios juristas prácticos. Para alcanzar esto, no basta con que el modelo propuesto sea -supongamos- científicamente acertado como tal, pues además tendría que resultar viable en las condiciones que ofrece la realidad jurídica misma. Entre ellas cuenta también, antes que nada, la circunstancia de que los operadores jurídicos puedan estar verdaderamente dispuestos a poner tal propuesta en práctica. Por tanto, sería indispensable que dicha propuesta metodológica tenga posibilidades efectivas de llegar a ser suficiente conocida - iy comprendida!- por esos mismos protagonistas. Debería ser susceptible de "prender" en la mente de los seres de carne y hueso que componen la dinámica real del derecho, estar en condiciones de funcionar con individuos que en general se caracterizan justamente por $N O$ cultivar los refinados hábitos de pensamiento que distinguen la especialización intelectual de epistemólogo. Pero, ¿es eso posible realmente?

Por mi parte, en distintos estudios he presentado unas radicales críticas de fondo frente a las corrientes dominantes en la actual Teoría del Derecho. Tales críticas tratan de llamar la atención, respecto a dichas corrientes, no menos acerca de su irrealismo que sobre su actitud general de solazarse en toda suerte de pedantismos escapistas, lo cual concierne tanto al primero como al segundo de los renglones antes señalados. Hasta donde tengo conocimiento, nadie ha respondido a las objeciones concretas expuestas 
por mí, ni quién viera cómo ingeniárselas para desautorizar las pruebas específicas, de texto y de hechos, que respaldan mis puntualizaciones. Pero aquí no voy a abocarme a reiterar o ampliar mis intentos de desenmascarar el carácter fundamentalmente ilusionista de planteamientos como los de la "Santa (charla-)Familia" (Rawls, Habermas, Alexy, etc.) 2, la lógica deónti$\mathrm{ca}^{3} \mathrm{y}$ en general las formulaciones de las semióticas formalistas ${ }^{4}$, el derecho "alternativo", etc. Me propongo "tomar por los astas" directamente, esto es, con independencia de lo que al respecto han imaginado esos autores $\mathrm{u}$ otros por el estilo, la cuestión de mayor relevancia práctica para la actividad cotidiana de los juristas: la pregunta acerca de si, y sobre todo cómo, sería posible elaborar menos "celestialmente" las sentencias judiciales mismas. Dando un paso más allá de mis críticas anteriores, primordialmente "negativas", voy a presentar unas indicaciones que tienen contenido "positivo", por así decir, para la Metodología del Derecho. Trataré de señalar directa y específicamente cuáles podrían ser, a mi juicio, unas vías REALISTAS -por contraposición a aquellas otras, esencialmente ilusionistas ${ }^{5}$ - para llevar a cabo el razonamiento jurídico profesional ${ }^{6}$.

Claro, lo más probable es que al fin de cuentas no sean muchos, si es que haya alguno, entre los operadores jurídicos que podrían poner tales pautas metodológicas en práctica, quienes efectivamente vayan a proceder así, llegado el caso. Pienso especialmente en los jueces... ¡si quisieran hacer tal cosa! Mas contra tal posibilidad obra no solo la circunstancia de que son bien remotas las posibilidades de que ellos vayan a leer estudios como el presente, sino algo muchísimo más fundamental: el hecho de que la "gramática" (Wittgenstein) de los juegos de lenguaje que conforman el universo discursivo derecho-en-la-práctica, corresponde a unas "formas de vida" cuyo sentido real es sobre todo de naturaleza retórico-persuasiva, donde sólo en orden secundario y en formas muy limitadas están llamados a jugar también algún papel los insumos de carácter propiamente empírico-racional ${ }^{7}$.

Pero el discurso jurídico profesional alberga no pocas inconsistencias en su propio seno, entre las cuales figura también la pretensión de presentarse,

${ }^{2}$ V. Haba 1996f, 1997 y 1998.

${ }^{3}$ V. Haba 1996a.

${ }^{4}$ V. Haba 2000.

${ }^{5}$ Aclaración.- Lo que he reprochado, por ejemplo, a "la Santa (charla-)Familia", no es que esos autores señalen tal o cual ideal de discurso, sino que los imaginarios practicantes de este sean confundidos con una "universalidad" de locutores de carne y hueso ante situaciones prácticas reales.

${ }^{6}$ Hasta ahora, a pesar de tenerlo bastante claro desde tiempo atrás, no había llegado a aclarar eso concretamente en mis trabajos ya publicados.

${ }^{7}$ V. Haba 1993, 1995c, 1996e y 1998. 
a pesar de todo, como si él constituyera una actividad intelectual de carácter científico. También ello forma parte de la retórica de este discurso mismo, por más que no concuerda mucho con cómo esos discursos son en verdad ${ }^{8}$. Y semejante pretensión conlleva, de todos modos, la consecuencia de que si hubiera unos operadores de dicho discurso resueltos a tomarse en serio lo de la cientificidad, resultaría un tanto difícil prohibirles que lo hagan así (al menos ante casos donde no actúen presiones demasiado fuertes en sentido contrario, sean gremiales o político-sociales, etc., para imponer determinadas soluciones). Dentro del radio de libertad del juez, y a fortiori en el de la doctrina, cabe inclusive - ¿por qué no?- la posibilidad de apoyarse en una información científica acreditada para fundamentar las sentencias. Es cierto que la formación tradicional de los juristas no facilita, ni mucho menos, que ellos posean un horizonte intelectual como para estar "abiertos" a conocer y aplicar tal posibilidad ${ }^{9}$. Así y todo, si las pautas metodológicas que señalaré son adecuadas y practicables para ejercer el oficio de jurista, para resolver casos discutidos en la esfera judicial, no veo por qué no pueda revestir algún interés hacerlas notar, ya que poner el acento precisamente en ese camino no es lo más habitual en estudios sobre el razonamiento jurídico ${ }^{10}$.

Para que un jurista ponga en práctica tales pautas necesitaría liberarse, antes que nada, de lo que más visceralmente ha introyectado en todos ellos su formación profesional: la "técnica" de confinar el razonamiento sobre el derecho a las exigencias de mutilación intelectual que le impone el normativismo jurídico. Si bien la forma más tradicional de éste aparece como superada, hasta cierto punto, en la mayoría de los estudios de Teoría del Derecho $^{11}$, no menos real es que, de una u otra manera, dicha orientación básica se mantiene en pie como dogma central de los razonamientos llevados a cabo por los juristas en el ejercicio normal de su profesión. Quiérase o no, el normativismo sigue "vivito y coleando" en la enseñanza proporcionada por las Facultades de Derecho, no menos que en los discursos de los Tribunales de Justicia. De ahí que también a la Teoría del Derecho le caiga como anillo

${ }^{8}$ V. Haba 1993: § III.

${ }^{9}$ El ejemplo ineludible (pero sólo por su inaudito éxito de audiencia) de esa cerrazón mental viene dado por los planteamientos centrales difundidos por el autor que en la actualidad es el propagandista más conocido de la ideología gremial con que se cubre la profesión jurídica: cf. Haba 2001a.

${ }^{10}$ Poco importa si lo que voy a señalar tiene o no tiene alguna originalidad. Lo que me mueve a hacer énfasis en esas pautas justamente, es el hecho de que, sea como sea, no transita por tales caminos el razonamiento de los juristas prácticos, ni suelen centrarse en ellas la generalidad de los estudios de Teoría del Derecho.

${ }^{11}$ La excepción más notoria, allí, son los simplismos avalados por el bestseller a que se refiere la nota 9, supra. 
al dedo: "Los muertos que vos matáis...". Tampoco una alternativa como la que señalaré aquí puede escapar a ese sino. ¡Al contrario! Pero también es verdad que, a diferencia de las orientaciones más difundidas en dicha Teoría, en todo caso tal modelo no contribuye a cohonestar, ni siquiera por unos atajos de pensamiento indirectos (las teorizaciones escapistas de toda laya), el sempiterno normativismo de la profesión jurídica. Por lo demás, como veremos al final, este se traduce hasta en la propia ética del discurso judicial

\section{El normativismo de los juristas (platonicismo juridicista)}

El normativismo jurídico se basa en la aplicación de la "Superstición del Unico Significado Verdadero"12 a la comprensión, específicamente, de lo que es derecho. Para ese normativismo, se trata de encontrar unas normas que de alguna manera se hallan pre-establecidas, con toda seguridad y precisión, en los textos del Derecho positivo, o hasta más allá de estos, en un "cielo" de los conceptos ${ }^{13}$ (p.e., ciertas "naturalezas jurídicas"). Difícilmente sea dable presentar una mejor caracterización sumaria de la actitud intelectual clave en que consiste el normativismo jurídico, que la siguiente:

"L. O. Thayer escribió (en 1898) sobre "aquel paraíso de los juristas en que todas las palabras tienen un sentido preciso y firmemente establecido; en el que los hombres pueden expresar sus intenciones no solo con exactitud, sino también con plenitud; y donde, si el escritor ha sido cuidadoso, el jurista, con el documento en cuestión delante suyo, puede, sentado en su mesa, inspeccionar el texto y responder a todas las cuestiones sin levantar los ojos"'”14.

Esas normas, el jurista piensa que las descubre simplemente. Descubre una norma jurídica como se descubre una estrella, solo que en otro lado: una en el firmamento, la otra en unos papeles. No menos ésta que aquella son, para él, algo que "está ahí", no hay más que "verlas"... O más bien, por lo habitual, lo que así se re-conoce es simplemente determinada estrella/norma ya vista antes por unos juristas eminentes que nos lo hacen saber así.

Tal descubrimiento se efectúa por unas vías de pensamiento que nada más consisten -se supone- en un "darse cuenta", mediante la inteligencia profesional, de aquello que la letra dice por sí misma, o de "la voluntad del legislador", o bien, en todo caso, de la "naturaleza jurídica" del instituto en juego, etc.. Cada una de estas cosas, o determinada combinación de ellas,

12 “.... la Superstición del Unico Significado Verdadero - tal como la ha denominado I. A. Richards-, lo cual puede tener consecuencias en cualquier campo del saber, y es fatal para cualquier pretensión de adelanto en el campo de la ética" [e igualmente en el del razonamiento jurídico] (Ch. L. Stevenson, Etica y lenguaje, trad. E. A. Rabosi, Bs. As., 1971: 86).

${ }^{13}$ Véase el clásico de Rudolf von Jhering, Broma y veras en la Jurisprudencia: Parte III.

${ }_{14}$ Transcrito en J. Frank, Law and the Modern Mind, Gloucester (Mass.), 1970 (ed. or. 1930): 202, nota 19. 
no puede implicar -se supone- más que una sola respuesta verdaderamente "correcta" para cada caso, en función de la disposición jurídica aplicable. En esta óptica, una vez que llego a conocer bien esas normas, ya sé todo lo que tenía que saber, en cuanto a lo "propiamente" jurídico. Como jurista, mi mundo intelectual se agota en saber desarrollar un pensamiento de orden pura y simplemente hermenéutico-intelectual respecto a normas cuyo contenido y alcance estaría ya fijado de antemano.

Así, el normativismo de los juristas impone una doble reducción del conocimiento, deformación profesional que amputa de antemano los posibles contactos entre pensamiento jurídico y realidad. a) Los normativistas reducen su conciencia, cuando pronuncian los discursos jurídicos al mero nivel de ciertos significados, en sí y por sí mismos, de unos juegos lingüísticos profesionales. Con ello se hace abstracción, completamente o poco menos, de las dimensiones prácticas de ese lenguaje: el normativista no se detiene a examinar qué repercusiones su discurso pueda tener (¡o no!) en los hechos. b) Incluso respecto a esos juegos de significados como tales, los normativistas tienen una visión simplista y en buena medida ficticia, pues no solo omiten plantear las indeterminaciones y antinomias que presentan las leyes y otros textos del Derecho positivo, sino que más bien contribuyen a encubrirlas mediante sus modos (dogmática, etc.) de exponer la normativa jurídica: "mito básico"15, "naturalezas" jurídicas y esencialismo en gene$\mathrm{ral}^{16}$, etcétera.

La impronta normativista en la formación profesional de los juristas hace que lo ahí enseñado consista, primordialmente, en repertorios conformados por la letra de unos preceptos del derecho positivo y las paráfrasis de estos ofrecidas en textos de estudio, a veces ampliadas mediante ciertas sutilezas dogmáticas. Ya lo decía Vaz Ferreira:

"Tienden también los estudios jurídicos a hacer espíritus formalistas y a $s a$ carlos de la realidad; a formar mentalidades acostumbradas a dar una importancia inmensa a las cuestiones de palabras, a las fórmulas, a las abstracciones, a las deducciones... Otra característica del estado mental que tan fácilmente se produce en los abogados, consiste en un respeto excesivo a las fórmulas hechas, a las prescripciones de los Códigos, como si no fueran dictadas por hombres" ${ }^{" 17}$.

Eso confina dicha enseñanza a la dimensión semántica, o poco menos. Mejor dicho, a unas entre sus posibles semánticas, al tipo de "lectura" (en-

${ }^{15}$ Basic Legal Myth: cf. el sensacional libro de Frank señalado en la nota anterior.

${ }^{16}$ V. Haba 2001c (Sec. B.II.3) y 2002 (Primera Parte: Sec. C.I.2).

${ }^{17}$ C. Vaz Fereira, Moral para intelectuales, Homenaje de la Cámara de Representantes de la República Oriental del Uruguay, vol. III, Montevideo, 1963 (ed. or. 1909): 69 s. Recuérdese asimismo las palabras de ese autor recogidas como encabezamiento del presente estudio, tomadas de su Lógica viva, Homenaje..., vol. IV, 1963 (ed. or. 1910): 145. 
tendimiento, manejo discursivo) de que tales textos son objeto cuando se invocan en el lenguaje propio de los profesionales del derecho; un sociólogo, por ejemplo, los "leería" de otra manera. Queda fuera de foco la otra dimensión de esos mismos juegos lingüísticos, los planos de su pragmática: las "formas de vida" (Wittgenstein) que conllevan, según los casos, las semánticas en cuestión.

En efecto, el normativismo consiste en $N O$ ir "más allá" del nivel semántico de unas normas, contentándose con aprehenderlas en ciertos planos de ellas que son acríticos por excelencia. El normativismo de los juristas les angosta la visión del mundo en forma tal que su conciencia social queda encogida, por lo menos mientras el pensamiento permanece dentro de ese plano, a lo que formulen los preceptos oficiales y sus versiones dogmáticas. Su mundo ( "cielo") es, simplemente, el de unos textos normativos. Para él se trata, en primer término y en último término, de lo que en estos se dice. NO se ocupa, ni poco ni mucho, de lo que con ellos se $H A C E$ (si es que algo se hace...).

$$
* * *
$$

Por más que haya tal o cual discurso, jurídico u otro, esto puede ser intrascendente en la práctica. También puede que esta última, aun invocando dicho discurso en todo o en parte, lo emplee para hacer cosas distintas de lo que sus locutores originarios (p.e., unos legisladores) se imaginaron. Al olvidar que las cuestiones prácticas no se resuelven con simplemente decir esto o aquello, ni aunque sea por escrito y con la unción del sello "derecho"- se cae en una miopía muy extendida, no solo entre juristas, a la que se puede llamar: platonismo (o fetichismo) de las reglas ${ }^{18}$. Tal tendencia está anclada, a su vez, en unas características más generales del pensamiento humano corriente: "magia verbal", wishful thinking, etc. ${ }^{19}$.

El platonismo de las reglas es un espejismo a que el jurista tiende en forma típica. Constituye, podría decirse, como una "enfermedad profesional de nuestro gremio" (Carrió) ${ }^{20}$, si bien creencias análogas son comunes también

${ }^{18}$ La expresión "platonismo de las reglas" (Regel-Platonismus) es de H. Rottleuthner, Rechtswissenschaft als Sozialwissenschaft, Francfort, 1973: 195. Frank se refiere con más detenimiento al mismo fenómeno, para el cual usa, entre otras calificaciones, la de rule-fetichism, o.c. (supra: nota 14): 165 y Apéndice II; en el libro de ese autor, véase los caps. VI a IX de la Primera parte, esp. los sitios que en el Index (403 s.) aparecen señalados bajo las rúbricas platonism y word-magic.

${ }^{19}$ V. Haba 2003b: $\S 12$.

${ }^{20}$ Dicho autor se refirió, con esas palabras, especialmente "a la proclividad a pesquisar la llamada "naturaleza jurídica" de una institución, de un hecho o de una relación que preocupa a los juristas, y a la facilidad con que estos entran en polémicas sobre el punto" (G. R. Carrió, Notas sobre derecho y lenguaje,. Bs. As., 1965: 73). 
fuera de él mismo: en las ideas políticas vulgares, en los parlamentos, en la dirigencia de instituciones públicas, etcétera. El normativismo jurídico es un hijo dilecto de ese platonismo. En efecto, ni más ni menos que un PLATONICISMO JURIDICISTA vienen a ser todas aquellas disquisiciones y discusiones sobre lo que "dicen" unos preceptos o principios, de cualquier sector del Derecho, cuando son llevadas adelante -como corrientemente sucede en la dogmática- con entera abstracción de fijarse en las posibilidades y en las consecuencias reales que esas normas, entendidas de determinada manera, puedan tener si llegan a ser aplicadas de tal manera en la práctica. Eso hace que, por lo general, lo más importante de todo no sea llamado a la cita: no forma parte del razonamiento "jurídico" lo de saber si en verdad están dadas las condiciones para que las normas en cuestión puedan realizarse como apriorísticamente se está dando por descontado. Se deja completamente fuera de foco cómo tales normas sean aplicadas de hecho en las condiciones sociales presentes. Se habla, y a menudo se discute, sobre ciertos preceptos jurídicos o unas figuras de la dogmática, sin preguntarse quiénes y de qué maneras podrán hacerlas cumplir en la práctica, a qué sectores sociales les serán aplicadas realmente, qué consecuencias microsociales o macrosociales se seguirán (¡o no!) de ello, etc. El normativismo es, por excelencia, el enclaustramiento extraempírico del pensamiento jurídico profesional.

En semejante hacer "rancho aparte" respecto a la dimensión practica de las normas invocadas reside la ceguera capital de todo platonismo de las reglas. Amparado en este, la dogmática jurídica se dedica a librar señeras lides (semánticas) en las que "resuelve", con solo dictar unas reglas o interpretarlas de cierta manera, los asuntos que sea. El jurista dogmático se queda muy orondo en ese "cielo de los conceptos jurídicos"... ipase lo que pase en la "tierra"! 21.

$$
* * *
$$

Dicho platonicismo se hace presente en dos fases. Por un lado, cuando se preparan proyectos de ley o reglamentos, a menudo los autores presuponen, implícitamente, que basta con establecer determinado cuerpo de normas, que ellos estiman las mejores, para que así, sin más, pasen a hacerse realidad ciertos objetivos perseguidos al legislarlas. Dan por descontado que también en la práctica se actuará conforme a tales normas y de acuerdo con dichos objetivos. Es, dicho sea de una manera gráfica, imaginarse que los preceptos tienen "patitas": que esas reglas son capaces de "caminar" por sí solas, y que lo harán ni más ni menos que según lo deseado por sus autores. Por otro lado,

${ }^{21}$ Supra: nota 13. 
ya ante cuerpos normativos en vigencia, se tiende a pensar respecto a ellos como si se tratara de un mundo per se; algo así como un topos uranos conformado según las ideas jurídicas establecidas en (aquellas que se imputan a) las disposiciones jurídicas.

Así, lo que los normativistas logran, más allá de que tal sea o no su propósito conscientemente, es desviar la atención de aquellos factores más decisivos para determinar la manera real como el Derecho está en condiciones de incidir, o no, en la resolución de esos asuntos. Nadie - itampoco la Sala Constitucional!- puede "leer" eso en el texto de las leyes o en la Constitución, ni en los eufemismos de la dogmática profesional. Las aplicaciones posibles de esos textos dependen de otras cosas: de la ideología y en general de la mentalidad que obre en la "cabeza" de aquellas personas que funcionan como sus intérpretes autorizados, en amalgama con variadas condiciones de la madeja social; en una palabra, todo aquello sobre lo cual $N o$ habla la enseñanza normativista. Si se hace abstracción de esos otros elementos, el fuera-del-texto (Debray ${ }^{22}$ ), entonces los textos del Derecho positivo -y a fortiori los de la dogmática jurídica- no sirven para saber gran cosa, en los casos discutidos por los juristas. Los textos solos ilustra poco, tanto para conocer como para impulsar la práctica del Derecho.

Es cierto que, en cuanto a esta práctica, no deja de haber renglones donde puede tener su importancia, a veces decisiva, la conciencia que los actores hayan adquirido sobre la existencia y lo que dicen esos textos justamente. Para un entendimiento realista sobre el derecho, tampoco es cuestión de caer en otro error, paralelo al del normativismo, y no mucho menos irrealista que este: tomar muy poco, o nada, en cuenta la normativa oficial promulgada por el Estado. Aunque no todo el espectro de lo que se edita como Derecho positivo, ni cada precepto tomado en particular, es algo que se aplica siempre, ni siempre es aplicado de la misma manera, es innegable que buena parte de la letra de ese Derecho y unas conceptualizaciones consagradas en la dogmática profesional de los juristas llegan a constituir, efectivamente, un "momento" de la dinámica real en la vida jurídica.

No es cuestión de calificar a los profesionales del derecho como "normativistas", en el sentido apuntado, porque se ocupen de normas jurídicas... ¡isino por la manera como lo hacen! Reconozco que ellas juegan un papel ciertamente importante dentro del razonamiento jurídico en general. La equivocación del normativismo no reside en el hecho de tomar en cuenta tal "momento", la dimensión semántica de las normas jurídicas, sino en: a) hipostasiarlo; y b) desgajarlo completamente de los otros "momentos" -variantes ideológi-

${ }^{22}$ R. Debray, Crítica de la razón política (trad. -con muchos defectos- Pilar Calvo), Madrid, 1983: 105 . 
co-interpretativas, condiciones socio-económicas y políticas, preferencias del intérprete, etc.- que le impartirán sus direcciones concretas a esas normas.

\section{Realismo jurídico como alternativa: orientación realista-crítica (generalidades)}

El propugnar una aproximación de índole realista-crítica respecto al derecho significa enfocar las cosas en forma muy distinta de las maneras como acostumbran a razonar los abogados, los jueces, los profesores en las distintas ramas del derecho positivo, etcétera.

¿Por qué, y en qué sentido, realista? A diferencia de la doctrina jurídica corriente, el realismo jurídico deja de lado toda "celestialidad" dogmáticoesencialista. Encara las normas jurídicas tal y como ellas son realmente, esto es, reconociendo sus indeterminaciones lingüísticas, en la medida en que estas se dan en el uso mismo de esos discursos, y además toma decisivamente en cuenta los resultados efectivos que cada norma tiene o no tiene -pragmática lingüística- en la realidad social. Las tendencias realistas comparten, en general, tres ideas fundamentales (habitualmente pasadas por alto en los discursos de los juristas), a saber:

"la insistencia sobre el abismo que existe entre la norma jurídica como esta aparece en los textos y lo que es en la realidad; una percepción de la falta de correspondencia entre el carácter abstracto de las normas generales y la individualidad de los casos concretos; y una conciencia de la naturaleza creadora de la función judicial" (Pekelis) $)^{23}$.

Digo además que esta es una aproximación crítica ya que, en virtud de ese mismo realismo, un enfoque de tal naturaleza no puede menos que resultar especialmente subversivo respecto a las formas de "ver" más comunes en la doctrina jurídica profesional. (Lo es asimismo frente a los variados tipos de orientaciones ilusionistas que llevan la voz cantante en la Teoría del Derecho: constructivismos racionalistas o "razonabilistas", lógica deóntica, semióticas formalistas, teorías del derecho "progresistas", etc.) El impulso crítico, en el sentido exigente de esta palabra, es decir, no en la acepción vulgar de aludir a un mero gusto o manía de "criticarlo" todo, consiste esencialmente en una ACTITUD (dirección) fundamental adoptada por la INTELIGENCIA. Entiendo que es adecuado caracterizarla señalando respecto a ella, en general, lo que Waismann destacó especialmente respecto al pensamiento filosófico:

${ }^{23}$ A. H. Pekelis, "La tecla para una ciencia jurídica estimativa" (trad. R. Sandoval); en Cairns/ Hall/Cowan/Pekelis/Frank/Patterson/Kelsen/Chroust, El actual pensamiento norteamericano, Bs. As., 1951: 121 s. 
"es atravesar esa costra muerta de la tradición y lo convencional, romper las cadenas que nos unen a preconcepciones heredadas, para lograr un modo nuevo y más amplio de ver las cosas" 24 .

Lo mismo vale, mutatis mutandis, para la sociología "cazadora de mitos" (Elias) y en general para el pensamiento innovador en todas las ciencias. Igualmente, también por lo que hace al pensamiento jurídico es muy cierto que, como subrayó Bachelard:

"El espíritu científico sólo puede constituirse destruyendo [¡crítica!] el espíritu no científico [p.e., normativismo]"25.

Esta observación, que dicho autor refería a lo que el llamó "ruptura epistemológica", se corresponde, de manera más general, con lo que Albert denomina el pensamiento de tipo "constructivo-crítico"26. Tipo de pensamiento que por eso mismo, por ser "crítico" en ese sentido, naturalmente provoca malestar en la inmensa mayoría de quienes se mueven al amparo del establishment académico. Es inevitable que la crítica a fondo choque con la inercia mental de la mayoría de los científicos de la propia disciplina, como así también con múltiples trabas burocrático-institucionales en general (movidas o no por algunos de esos mismos científicos) ${ }^{27}$.

"Realismo "y "crítica" son, si bien se mira, dos caras de una misma moneda. Una visión realista sobre los discursos jurídicos suele llevar a ubicarse críticamente asimismo respecto a la realidad del derecho, a no apartar para nada la vista de cómo es esta misma. Los enfoques realistas-críticos no pueden desentenderse de considerar si las normas jurídicas en cuestión, vale decir, unas u otras interpretaciones de estas, de veras sirven con vistas a alcanzar los objetivos sociales a los que se supone dirigida esa regulación; problemática frente a la cual, en cambio, tanto el pensamiento jurídico corriente como las corrientes dominantes en la Teoría del Derecho se conforman con refugiarse cada cual en su "cielo" propio.

“... la construcción del conocimiento sólo es posible como crítica a las ideas recibidas. (...) Conocer significa lucha crítica con las ideas subsistentes” (O. Bollnow, Introducción a la filosofia del conocimiento, trad. W. Kemp,. Bs, As., 1976: $111 \mathrm{s.})$.

\footnotetext{
${ }^{24}$ F. Waismann, "Mi perspectiva de la filosofia”; en A. J. Ayer (Ed.), El positivismo lógico, Madrid, 1978: 378 s.

${ }^{25}$ G. Bachelard, La filosofia del no (trad. N. Fiorito de Labrune), Bs. As., 1973: 11.

${ }^{26}$ H. Albert, Traktat über rationale Praxis, Tubinga, 1978: 59.

${ }^{27}$ Para mencionar un ejemplo que conozco del modo más directo: todas las puertas del establishment iusacadémico en España ( y también otras en Francia), con la solitaria excepción de Doxa, me fueron cerradas para publicar una crítica sin contemplaciones a las simplezas del Sr. Dworkin: Haba 2001a.
} 
"Los grupos con pensamiento científico son, en principio, grupos que critican o rechazan las ideas colectivas dominantes en una sociedad, aunque [éstas] se apoyen en autoridades reconocidas, porque [aquellos] han comprobado, a partir de investigaciones concretas y sistemáticas, que esas ideas colectivas no se corresponden con los hechos observables. Los cientificos, con otras palabras, son cazadores de mitos; se esfuerzan por sustituir imágenes de secuencias factuales, mitos, creencias y especulaciones metafísicas, no comprobables sobre la base de la observación de hechos, por teorías, es decir, modelos de interrelaciones susceptibles de control, comprobación y corrección mediante observaciones de hechos. (...) [Pero] tanto dentro como fuera del grupo de los científicos especializados existe con mucha frecuencia inclinación a transformar las teorías científicas en sistemas de creencias [dogmáticas]. Se procede a ampliaciones [hipostasiamientos, falsas generalizaciones, esencialismos, wishful thinking, etc.] o a utilizaciones de esas teorías de un modo que no [se] justifica [por] la ulterior observación, guiada por la teoría [no ilusionista], de los hechos" (N. Elias, Sociología fundamental, trad. G. Muñoz, Barcelona, 1982: 62 s.).

No es que por tratar de manera realista-crítica las cuestiones jurídicas se pretenda decir que no hay normas de derecho positivo, ni sostener que por lo general carecen de importancia práctica. Al contrario, para ser verdaderamente realista en este terreno, hay que empezar por reconocer que tanto en la actividad del jurista profesional como en las conductas sociales en general, las normas en que se cree llegan a tener influencias considerables ${ }^{28}$. Tales normas intervienen como unas guías - no guías herméticas, per o guías al fin- de nuestra conducta. Es inimaginable una sociedad moderna, ni tampoco las antiguas, sin que haya ahí ciertos "programas" que están (más o menos) en la "cabeza" de la gente, especialmente en las de los juristas, para que los individuos sepan (más o menos) cómo actuar en distintas circunstancias. [En qué medida unas personas, pocas o muchas, vayan o no a seguir estrictamente las indicaciones de esos programas, pero también la cuestión de saber cuándo tales indicaciones son bastante precisas: ¡eso es otro asunto!] La presencia necesariamente de tales programas, ya sean más o sean menos elásticos, en relación con numerosas especies de actividades, está más allá de toda duda; si ellos faltaran del todo, nadie sabría, ni siquiera aproximadamente, a qué atenerse en gran parte de las relaciones con sus semejantes

\footnotetext{
${ }^{28}$ Recuérdese lo que en sociología se conoce, desde 1931, como Teorema de Thomas: "Si los hombres definen [se imaginan] las situaciones como reales, estas son reales en sus consecuencias". Téngase presente también que las normas jurídicas forman parte precisamente de aquella "construcción" social de la realidad que en la mente humana interviene como un factor determinante de sus conductas. Cf. P. Berger / T. Luckmann, La construcción social de la realidad (trad. S. Zuleta, rev. técn. M. Giménez Zapiola), Bs. As., 1968: esp. §§ II.1.e y II.2.c.
} 
Y lo de "realista-crítico" tampoco significa proponer que una investigación de tipo jurídico deba ser más o menos lo mismo que las investigaciones en otras ciencias sociales. Por ejemplo, no será igual que una investigación propiamente sociológica sobre el derecho, la cual consista en describir pautas habituales de conducta en relación con cierta esfera del derecho. No es lo mismo una forma frecuente de conductas, seguida de hecho, lo investigado ahí por el sociólogo, que el programa jurídico que se tiene en la cabeza -aunque fuere para violarlo o para cumplirlo de maneras distintas- al realizar esas conductas. Es en esto último, el "programa", sobre lo que ha de centrarse una investigación de tipo jurídico; aunque sea, si cabe, para poder tener en cuenta en qué medida y por qué no se cumple cabalmente con las instrucciones de aquel, a pesar de haberse considerado deseable su acatamiento al establecerlo. El "programa" ayuda a explicar mucho, aunque no todo, de las conductas que se relacionan con el derecho, inclusive de unas que en mayor o menor medida tienden a desligarse de él. Sí, también lo que se piensa como derecho positivo constituye un factor -entre otros- de la realidad jurídica misma.

Pero si bien los exámenes de tipo realista-crítico no desestiman la influencia de las normas jurídicas, inclusive la manera cómo estas sean "vistas" por la doctrina del derecho, ellos tampoco sobrestiman eso... “¡ahí está el detalle!”. En esto último reside la diferencia esencial con los enfoques más corrientes al respecto. Los realistas no se hacen ilusiones míticas sobre las normas: no sólo en cuanto a que éstas se hallen simplemente "contenidas" en los textos del derecho positivo, tampoco sobre la posibilidad de inferirlas de algún cielo discursivo de racionalidades o razonabilidades. Tienen bien claro que no hay, ni puede haber, método alguno -ni científico, ni "razonable", ni "dialéctico" o de la Razón "comunicativa" o como mejor quiera llamársele- para deducir un sentido solo, o el "mejor", etc., respecto a las normas cuyo significado se discute en la práctica. La decisión sobre cómo entender los textos de derecho no depende, pues, de estos en sí mismos sino de otras cosas, sean cuales fueren, en atención a las cuales el intérprete OPTA. Tal opción él la realiza bajo influencias de orden social, psicológico-personales, académico-intelectuales, etc.: todo un mundo de factores que son no menos DECISIVOS que VARIABLES para determinar tanto lo que el derecho "dice", según unos u otros intérpretes, como así también lo que él venga a ser en los hechos. Respecto a ese mundo -la tierra, decía Jhering-el discurso jurídico corriente se dedica a hacer mutis por el foro... (y buena parte de la Teoría del Derecho, a disputar sobre jerigonzas acerca de cómo mejor mirar hacia las nubes). Por el contrario, la aproximación realista-crítica se encara con el discurso jurídico para aprehenderlo y para manejarlo con vistas a cómo este funcione EN LA PRÁCTICA. 


\section{Punto de partida metodológico: dos presupuestos básicos}

(la necesidad de optar)

El realista reconoce, sin disimulaciones y también sin recurrir a unos eufemismos "técnicos" para decirlo más diplomáticamente, el hecho básico de que a menudo los textos jurídicos cabe entenderlos de maneras distintas, ninguna de las cuales es ni más ni más ni menos "correcta" que las demás; mas tampoco afirma que esto sea así en todos los casos. Cuando en la discusión sobre el sentido de un texto jurídico se manejan, por ejemplo, solo dos interpretaciones, entonces el texto no tiene, en realidad, un solo sentido; tiene por lo menos dos, en ese medio (si bien es posible, siempre, concebir otras interpretaciones aún, podemos prescindir de ellas en la práctica). Tales significados no dependen, en sí mismos, de la voluntad del locutor, cualquiera sea el sentido preferido por él mismo: aquellos están ahí, en dicho medio. La pregunta crucial es: ¿qué haré yo, como jurista llamado a aplicar (o no) dicha disposición, ante esos dos sentidos, ya que no puedo aplicar ambos a la vez? Pues bien, la orientación realista-crítica tampoco deja completamente abandonado a su suerte al jurista en esa encrucijada. Ella le suministra, de todas maneras, algunas indicaciones capaces de orientarlo al respecto, justamente para que él no pueda evadir su responsabilidad con excusas como las ofrecidas por los mitos sobre la existencia del único significado jurídico "correcto", o el "mejor", etc. Esas indicaciones parten de dos presupuestos sine qua non:

Primer presupuesto.- Dicha orientación comienza por advertirle al jurista, antes que nada, eso que no me cansaré de repetir: "Comprenda que no hay Dios, ni "letra", ni "espíritu de la ley" o "voluntad del legislador", ni modelo ideal de "racionalidad" (dialogal o no dialogal), ni ninguna otra cosa, que le vayan a resolver ese problema en lugar suyo. ¡Decide USTED, no busque disimular este HECHO!". El intérprete del derecho puede someterse a cualquiera de dichas "cosas", o inspirarse en otras figuras de su dogmática profesional; pero aun así, al inclinarse ante una de esas instancias, no es otro que él mismo quien ha decidido tomar justamente esta como criterio de resolución.

Segundo presupuesto.- Ahora que, si bien el intérprete no puede salvarse de tomar ahí una decisión PROPIA, no menos cierto es que puede someter su decisión a unas $u$ otras formas de proceder. Puede decidir con base en una toma de posición razonada, lo más científica y autoconsciente posible, etc. O bien, en cambio, puede decidir a "pálpito", o algo por el estilo. O puede limitarse a seguir una línea de soluciones acostumbrada, sin reflexionar mayormente sobre ella, ya sea la de determinada jurisprudencia o la doctrina que le enseñaron a acatar ciertos profesores prestigiosos. $\mathrm{O}$, también, puede decidir en función de unas presiones sociales, o directamente personales, a 
que se encuentre sometido. Etcétera... ¡Hay maneras y maneras de elegir! De ahí que la aproximación realista-crítica no se limite simplemente a subrayar el carácter optativo de toda interpretación jurídica, sino que pone al jurista ante su propia responsabilidad asimismo en cuanto a lo siguiente: "Sepa también que usted puede, si es que quiere (aunque nada ni nadie le "obliga" a hacerlo así), decidir las cuestiones jurídicas de otra manera que la mayoría de sus colegas, si es que usted, a diferencia de ellos, entre las opciones interpretativas viables procede a elegir con base en recursos que ofrece el pensamiento de orientación empírico-racional". Esto significa resolver siguiendo determinadas vías de examen que, sin perjuicio de mantenerse dentro de unos marcos que son especificamente jurídicos, al mismo tiempo ellas son implacablemente realistas e insobornablemente críticas.

Dichas vías pueden consistir, heurísticamente ${ }^{29}$, en una secuencia de cuatro "momentos". Se trataría, a mi juicio, de los pasos siguientes: 1) se empieza por trazar un cuadro de las interpretaciones jurídicas que en el presente sean posibles, de acuerdo con doctrinas jurídicas de recibo entre los juristas del medio, para los preceptos de derecho positivo traídos a colación [momento lingüístico-dogmático]; 2) a continuación, se procede a reconstruir el discurso de los preceptos de derecho invocados y de dichas doctrinas, para hacerlo lo más transparente posible, esto es, sacando a luz la verdadera "gramática" de esos juegos lingüísticos y sobre todo haciendo ver sus principales "trampas" (indeterminaciones fundamentales, precomprensiones no tematizadas pero decisivas, alternativas ideológicas, alcances persuasivo-emocionales, etc.) [momento analítico-crítico]; 3) después habrá que detenerse a delimitar con precisión la finalidad que el intérprete señale (decida) como objetivo práctico de esos preceptos, entre las jurídicamente posibles (de acuerdo con ideologías aceptadas) en su medio social para los preceptos invocados [momento axiológico-teleológico]; 4) finalmente, relacionando entre sí los tres pasos anteriores, corresponde escoger, de lo reconocido en (1) y (2), aquella interpretación que sirva como el medio más eficaz para que el objetivo (3) pueda ser verdaderamente realizado en la práctica [momento empírico-instrumental] .

\section{Paso inicial: lingüístico-dogmático (el "marco" o "partitura"} jurídico-positivos)

La contestación jurídica acerca de una cuestión no es una respuesta libre. No lo es, pues se entiende que ésta ha de corresponder ni más ni menos que a unos juegos de lenguaje que constituyen determinado universo discursivo,

\footnotetext{
${ }^{29}$ Esto es, no se trata de una metodología de tipo positivo-estandarizante sino esencialmente de carácter heurístico-negativo: v. Haba 1997 (§ I), y 2000 (Parte II).
} 
alguna de las específicas "gramáticas" (Wittgenstein) de la región lingüística llamada derecho. Esos juegos son los dogmas, las bases convencionales a que está sometida la posibilidad de "hablar" en el idioma-derecho. Ellos conforman el "marco" normativo (Kelsen) ${ }^{30}$, la "partitura" (Frank) $)^{31}$, dentro de cuyos límites opta el jurista para dar esa clase de contestación, mientras este no evada su condición de tal.

Dicho universo lingüístico contiene básicamente tres órdenes de discursos en interacción: letra del derecho positivo, jurisprudencia, postulados doctrinarios; y también penetran ahí, desde luego, las ideologías generales suprajurídicas ( "universos simbólicos"32) vinculadas íntimamente con ellos. Como todo eso da lugar, en numerosas situaciones, a interpretaciones divergentes, resulta que el marco en cuestión está conformado, para cada caso o tipo de casos, por aquellas respuestas que al respecto sean de recibo en el gremio de los juristas; esto es, tanto las que aceptan unos como las que aceptan otros, por más que ellas resulten relativamente contradictorias entre sí.

Para buscar una respuesta de derecho (positivo) es indispensable, pues, empezar por reconocer ese marco en lo pertinente, detectar qué respuestas a la cuestión planteada caben en su interior. No se trata simplemente de buscar una solución que pueda resultar conveniente, útil desde algún punto de vista. Ella ha de estar en condiciones, primero que todo, de corresponder al lenguaje-derecho según es entendido de acuerdo con la conciencia lingüística jurídico-profesional del medio, ya sea por todos o parte de los especialistas en esta disciplina. La enseñanza universitaria del derecho consiste ni más ni menos que en eso: aprender a usar tal lenguaje especializado de la manera como esto se hace en el gremio de los juristas, o sea, proporcionar las habilidades lingüísticas necesarias para manejar profesionalmente los repertorios de topoi que constituyen los "dogmas" del universo-derecho. Por más encomiable que, desde algún punto de vista, sea una solución a determinado problema, tal solución no puede solicitarse jurídicamente, esto es, ante los tribunales o en general a las autoridades estatales, si ella no es susceptible de responder a lo que se reconoce como establecido en el universo lingüístico del derecho positivo vigente. Mas esos topoi no sólo son múltiples y variados, sino que incluso llegan a contradecirse entre sí: no configuran un "sistema" propiamente dicho, sino que brindan, llegado el caso, la posibilidad de elegir entre distintas opciones a los intérpretes de las leyes u otras disposiciones jurídicas ${ }^{33}$

\footnotetext{
${ }^{30}$ Cf. H. Kelsen, Teoría pura del derecho (trad. R. J. Vernengo), México, 1982: 351 s.

${ }^{31}$ Cf. J. Frank, "Palabras y Música “ (trad. R. J. Vernengo), en El actual pensamiento norteamericano (o.c. supra: nota 23).

${ }^{32}$ Cf. Berger/Luckmann, o.c. (supra: nota 28).

${ }^{33}$ V. Haba 1972 y 2003 b (esp. $\S 21$, caps. VII y IX).
} 
En síntesis.- El primer paso propio de todo discurso jurídico es "ubicarse" en el derecho, vale decir, re-conocer las respuestas alternativas que caben dentro de él, de acuerdo con las costumbres lingüísticas manejadas al respecto en el gremio de los juristas. En otras palabras, es saber distinguir las respuestas jurídicas posibles, en un entorno histórico-social dado, de las que no lo son ya o de las que no lo son aún; todo ello en función de los márgenes que se toleren dentro de la conciencia jurídico-lingüística vigente en la práctica. Una vez reconocidas esas respuestas para el punto en discusión, el locutor jurídico, si actúa como tal, no tiene más remedio que optar entre estas mismas nada más, sea o no que haya otras posibilidades preferibles desde otros puntos de vista (religiosos, morales, políticos, utilitarios, etc., siempre que estos no sean reconocidos como parte también del propio universo-derecho). Los tres pasos que siguen consisten en requisitos para efectuar una elección racional entre esas respuestas posibles.

Acotación.- Lo dicho no implica negar que también en muchos casos hay textos del derecho que se entienden de ciertas maneras que nadie discute. No pretendo afirmar que todo en el derecho sea discrepancias; en tal caso se viviría en un completo caos, ninguna sociedad puede resistir más que ciertos grados de incertidumbre sobre lo establecido como normas oficiales de convivencia. Existen numerosas disposiciones jurídicas que, sea por las razones que fuere, aparecen como indiscutibles en todo o en partes sustanciales de su contenido preceptivo, por lo menos durante un tiempo. Respecto a las disposiciones que de hecho se entienden uniformemente, y mientras ello sea así (esto puede cambiar ante nuevas situaciones o por influencias de ideologías sociales), bien puede decirse que los textos jurídicos respectivos son "claros", que su sentido no admite dudas. Las incertidumbres que importan son aquellas que se dan en la práctica misma del derecho: por ejemplo, cuando lo que se discute es justamente la "claridad" de cierta disposición [Haba 2003b: $\S 40$ ] y en general cuando se trata de conceptos jurídicos muy indeterminados [Haba 2003b: cap. VII].

\section{Segundo paso: analítico-crítico ("higienización" del discurso jurídico)}

El momento anterior habrá permitido poner netamente sobre el tapete las alternativas de solución jurídica posibles, de acuerdo con el Derecho positivo considerado, como es entendido en la actualidad. Pero no pocas veces resulta que incluso las doctrinas invocadas contienen, a su vez, sus propias nociones indeterminadas. Es posible que también esas alternativas mismas, ya sea todas o algunas, no estén presentadas de modo suficientemente preciso. Aun ellas pueden acaso admitir, respectivamente, más de una interpretación concreta, por aparecer formuladas mediante unos giros lingüísticos (p.e.: "dignidad”, "soberanía”, "justo precio", "razonable”, etc.) que dificulten saber a ciencia cierta si tales o cuales conclusiones prácticas se desprenden necesariamente de ellas mismas. 
Esa indeterminación de segundo grado, por así decir, no es inusual. Nada tiene de extraño, habida cuenta de que los discursos jurídicos - no solo los textos legales, sino inclusive las opiniones doctrinarias invocadas para interpretarlos- suelen recoger buena parte de las indeterminaciones propias del lenguaje corriente y también plegarse a sus ingenuidades ( "trampas") más corrientes. A menudo ellos contienen unos giros básicamente retóricos, sin que estas características propias del lenguaje vulgar sean advertidas, como tales, por sus locutores profesionales. Si no se empieza por tomar el cuidado de que inclusive dichas interpretaciones sean debidamente "higienizadas", esto es, sacar a luz sus indeterminaciones claves y efectos emocionalizantes que las inmunizan contra todo cuestionamiento propiamente racional, no será posible manejarlas para niveles de examen científico-empíricos, de la manera requerida por los dos pasos siguientes, sobre todo el cuarto. De ahí que no pocas veces resultará indispensable "traducir" las alternativas presentadas a un lenguaje más preciso, reformulándolas de modo que tales o cuales de sus propias nociones claves ya no resulten susceptibles de ser manipuladas a piacere por unos o $\mathrm{u}$ otros locutores jurídicos.

Quiere decir que es necesario empezar por reconstruir el planteamiento de cada interpretación jurídica presente, en lo indispensable para determinar a ciencia cierta cuáles son específicamente las soluciones PRÁCTICAs que cada una implica. Para ello habrá que re-formularlas en un lenguaje netamente intersubjetivo y de inequívoca referencia empírica. El jurista realista tendrá que abocarse, antes de seguir adelante, a des-enredar unos "nudos" típicos como los siguientes (entre otros), en los discursos jurídicos presentes: distinguir netamente entre cuestiones de palabras y cuestiones de hechos (p.e., poner de manifiesto lo que son unas meras disputas sobre clasificaciones); diferenciar entre cuestiones explicativas y cuestiones normativas (como así también, de manera todavía más general, entre asuntos de "es" y de "debe": desacuerdos valorativos encubiertos, etc.); no dejarse marear por falacias verbo-ideológicas (pero tampoco caer en el extremo opuesto: falsa precisión), aclarar conceptos jurídicos indeterminados y desenmascarar fórmulas vacías pseudonormativas; no sucumbir a la magia verbal y, en general, arrancar del "cielo" los planteamientos de orden esencialista (p.e., "naturalezas" jurídicas" o los discursos extrapragmáticos sobre "derechos humanos"), etc. etc. .... ${ }^{34}$.

\footnotetext{
${ }^{34}$ Respecto a cada uno de esos puntos, v. Haba 2003b: caps. II (esp. §§ 11-13) y VII (esp. $\S 62$ ). V. también Haba 2001c (Sec. D.I.3: sobre "naturalezas jurídicas") y 2003a (sobre "derechos humanos").
} 
Este "momento" responde, pues, a una dirección que esencialmente es de carácter discursivo-analítico y crítico-racional ${ }^{35}$. ANALítico: en cuanto "desmenuza" (por así decir) las interpretaciones doctrinarias presentes, sacando a luz unas indeterminaciones claves que afectan básicamente la posibilidad de discernir en forma intersubjetiva a qué apunta en la práctica la formulación lingüística examinada. CRíTICO: porque ese examen sirve para poner de manifiesto, a la vez, unos vicios de pensamiento -variadas falacias implícitas- que suelen "montarse" (por así decir) en confusiones típicas que dominan en el entendimiento lingüístico vulgar, de donde suelen ser incorporadas sin más a variadas formulaciones jurídicas.

\section{Tercer paso: axiológico-teleológico (delimitación del objetivo práctico)}

Una vez determinadas netamente, en relación con la cuestión discutida, las respuestas jurídicas posibles de acuerdo con el Derecho positivo (los dos momentos anteriores), no hay otra salida, si nos mantenemos dentro de él mismo, que elegir entre ellas. Cualquiera sea la escogida, esta regulación ocasionará, al aplicarla en la práctica, ciertas consecuencias de hecho, para muchas o pocas personas. Por eso, si a diferencia del jurista dogmático no se razona como si las normas tuvieran su fin en ellas mismas, habrá que plantearse, en vista de su aplicación práctica, la pregunta principal: ¿para qué sirve, o debieran servir, las disposiciones jurídicas consideradas? Es poner sobre el tapete la cuestión de los fines PRÁcticos a que esté destinada tal o cual disposición.

Probablemente resulte que si se aplica una de las interpretaciones se den ciertas consecuencias prácticas, mientras que si se aplica otra se produzcan consecuencias diferentes. Resulta, pues, que la primera interpretación coadyuva a realizar el fin A y la segunda al fin B, en la práctica. Esos fines pueden resultar, de hecho, más o menos incompatibles. Cuando el interprete elige una interpretación, con esto acepta también, sea o no consciente de tal implicación, el fin práctico para el que sirve esta misma; y al rechazar una interpretación, está rechazando asimismo el fin práctico favorecido por esta otra. Si un fin propuesto es aceptado o rechazado, significa que al respecto se formula una apreciación de orden valorativo, sea en sentido positivo (aprobación) o negativo (desaprobación). Lo que el intérprete hace al elegir uno de los sentidos posibles, es ni más ni menos que efectuar, así sea implí-

\footnotetext{
${ }^{35}$ Como ilustración en cuanto a ensayar un análisis orientado en el sentido de este segundo momento, puede verse el examen que sobre una decisión de la Corte Interamericana de Derechos Humanos presenté en mi Tratado básico de derechos humanos, t. I, Juricentro, San José, 1986: 417 ss. Véase también el apartado "Un ejemplo muy neto de normativismo judicial", en Haba $2001 b$.
} 
citamente, un juicio de valor positivo respecto a las consecuencias prácticas que esa interpretación esté en condiciones de producir.

En efecto, el derecho está al servicio de valores. De ahí que las disposiciones jurídicas se interpreten, señaladamente cuando su contenido específico es objeto de controversias, según cuáles sean los valores a que el intérprete entienda, explícita o implícitamente, referida la finalidad de esa normativa. Pero los principales valores que normalmente se señalan para el derecho suelen indicarse mediante lo que son más bien unas fórmulas vacias: "justicia”, "libertad", "bien común”, “intereses nacionales”, etc... La "vaciedad", o en todo caso una semi-vaciedad, de esas fórmulas reside en el hecho de que pueden ser-iy de hecho son!- entendidas de las más variadas maneras, según los intereses o las preferencias ideológicas de quienes las invocan en la retórica del discurso público, sea político, jurídico, religioso, etc. ${ }^{36}$ No hay ninguna respuesta dada a título de jurídica que no pueda presentarse, de una u otra manera, como dirigida a promover algunos de, cuando no todos, esos grandes valores.

La relación de una interpretación jurídica con la realización de tal o cual valor no puede apreciarse con cierta nitidez si no se empieza por fijarle características precisas al valor invocado, en cuanto a su aplicación para la cuestión práctica específica de que se trate. Esto es: el jurista realista necesita saber, de manera bien determinada, a qué grupos de personas y en qué "cosas" deba beneficiar concretamente la puesta en práctica de ese valor ahí; como así también cuáles grupos y en qué serán perjudicados por ella, y quiénes no serían tocados ni para bien ni para mal por la solución propuesta. Más que pensar en unos grandes valores en abstracto, la valoración básica que se adopte tiene que consistir, para poder sacar consecuencias netas de ella, en tener bien claro para qué fines prácticos ESPECÍFICOS - ¿favorecer a quienes (muchos o pocos) y en qué?- se busca que sirva la interpretación jurídica por escoger.

Una vez que el intérprete haya adoptado su decisión sobre esto último, se le plantea otra pregunta decisiva: ¿cómo coadyuvar a que el cumplimiento de los fines escogidos, especialmente ellos, sea lo que realmente se produzca como un resultado de la normativa jurídica aplicable? Lo que él tiene que tratar de averiguar ahora, por tanto, es cuál de las interpretaciones jurídicas posibles ofrece las mejores probabilidades de servir para apoyar en la práctica la realización de esos fines justamente. Pero ésta, a diferencia de las dos preguntas anteriores, no es un asunto ni de orden esencialmente lingüístico ni tampoco de naturaleza básicamente valorativo-optativa. Constituye ni

\footnotetext{
${ }^{36}$ V. Haba 2003b: $§ 62$.
} 
más ni menos que una cuestión de hechos. Para abordarla, es indispensable examinar la realidad social. De esto se trata en el momento siguiente, como etapa conclusiva indispensable para completar un razonamiento jurídico que consiga ser propiamente realista.

\section{Paso final: empírico-instrumental (jtomar en cuenta la realidad} social!)

Los tres pasos precedentes habrán permitido ya saber cuáles son las alternativas de solución jurídica entre las que el intérprete tiene que escoger (momentos 1 y 2) y determinar con suficiente precisión las finalidades prácticas (momento 3) que la solución por escoger ha de contribuir a hacer efectivas en el mayor grado posible en su medio social. Ahora bien, tal posibilidad no depende simplemente de los buenos deseos del intérprete autorizado. Depende sobre todo de cómo las gentes (pocas o muchas) con cuya conducta - acciones u omisiones- es indispensable contar para cumplir dichas finalidades actúen en los hechos. Hasta donde esto pueda preverse, a veces con grados de probabilidad mayores y otras no tanto, eso se ocupan de investigarlo distintas ciencias sociales, cada una de las cuales trata en especial sobre cierto género de los múltiples aspectos en que se manifiestan los comportamientos humanos: antropología, sociología, economía, psicología, etc. Esas ciencias sacan a luz regularidades en tal sentido, ya sea de orden más general (tendencias universales de los seres humanos o las propias de un tipo de cultura o en cierto nivel de estratificación social, etc.) o más particulares (en una sociedad determinada o un grupo dentro de ella, o en cierta clase de ocasiones, o unos comportamientos típicos de las personas ubicadas en determinada capa social o los de determinado tipo psicológico, etc.).

Hay muchas cosas que son relativamente previsibles en la conducta de las personas, por lo cual cada quien sabe más o menos a qué atenerse en sus relaciones con los demás en numerosos aspectos. Claro, no pocas veces nos llevamos sorpresas al respecto; pero eso no quiere decir que siempre, y ni siquiera en la mayoría de los casos, sea así. Mucho de lo previsible son cosas que llegamos a saber simplemente por nuestra experiencia cotidiana. Mas también hay elementos decisivos de la realidad social que, no obstante constituir constancias básicas (por lo menos tendencialmente), resultan menos perceptibles "a simple vista", aun cuando tales factores intervienen decisivamente para determinar lo que hacen o dejan de hacer amplios grupos de personas, configurándose así la "madeja” normal de comportamientos societales corrientes.

Esto último, aquello que por lo general la gente no advierte pero obra por debajo y sobre los comportamientos captados por cualquiera, constituye el principal objeto de investigación en las ciencias sociales. Ellas ofrecen 
señaladamente dos rubros de conocimientos especializados: a) revelan ciertas tendencias de orden general actuantes en el seno de una sociedad o en determinado sector de ella, las cuales intervienen allí ya sea en forma bastante permanente o coyuntural; b) advierten qué efectos reales pueda tener, en función de semejantes tendencias, la ejecución de ciertas medidas destinadas a influir sobre la conducta de miembros de esa sociedad, sean muchos (instituciones u otros grupos sociales) o pocos (los protagonistas de determinado caso: p.e., una terapia psicológica para Fulano, una política comercial para la empresa $\mathrm{X}$, etc.).

En cuanto a (b), se trata de situaciones donde, justamente, las medidas consideradas se examinan en relación con un fin, el de producir ciertas consecuencias prácticas, para las cuales dichas medidas puedan constituir (¡o no!) un medio idóneo. El científico social está, o debiera estar, ahí para aclarar si el medio en cuestión sirve o no sirve para la finalidad perseguida. En tal sentido, su palabra constituye un juicio de valor de carácter instrumental $^{37}$, en el sentido del modelo weberiano de Zweckrationalität (racionalidad con arreglo a fines $)^{38}$. Los científicos sociales son los especialistas en este tipo de juicios cuando la realización del objetivo depende de si en la práctica sea viable lograr que se lleven a cabo de determinadas maneras unas conductas interpersonales. Tal, ni más ni menos, es también el caso de los fines perseguidos mediante una regulación jurídica. Cuando los medios para lograr esos fines no son obvios, o sea, si conocer tal cosa no está simplemente al alcance del "buen juicio" del ciudadano común, entonces nadie mejor que el científico social, de la rama pertinente, para aclararle al jurista cuál de las distintas soluciones jurídicas presentes, entre las interpretaciones posibles de los textos invocados, pueda estar en condiciones realmente de impulsar el efectivo cumplimiento de cierto fin práctico (formulado con suficiente precisión, claro está).

Síntesis.- En el cuarto momento, paso final del razonamiento jurídico realista, el intérprete examina, ya sea por su propia cuenta -si ello está al alcance del conocimiento corriente sobre la realidad social en su medio- o recabando la información pertinente de uno o más científicos sociales, cuál de las distintas interpretaciones lingüístico-dogmáticamente posibles para los textos jurídicos invocados (momentos 1 y 2) promete ser la más eficiente, o acaso la única eficiente entre ellas, como MEDIo práctico para realizar en los hechos cierto objetivo específico -valor/fin- netamente delimitado (momento 3). - Entre las interpretaciones posibles del derecho positivo

\footnotetext{
${ }^{37}$ Cf. C. G. Hempel, La explicación cientifica (trad. N. Míguez), Bs. As., 1979: cap. III.7. Véase además A. Brecht, Teoría Política (trad. J. M. Mauri), , Barcelona, 1963: esp. 122-131.

${ }^{38}$ V. Haba 1980.
} 
vigente, el jurista común elige con la mirada puesta en algún "cielo" meramente dogmático-doctrinario. También el jurista realista elige entre aquellas mismas, pero opta no en función de razones esencialmente "celestiales", sino con base en unas consideraciones severamente empíricas: se decide por la interpretación que tenga mayores probabilidades, científicamente sostenibles, de ser un medio eficaz para conseguir realizar EN LA PRÁCTICA determinado fin social bien delimitado.

\section{Epílogo: Realismo jurídico como ética de la responsabilidad judicial} (;Contra la Razón jurídica trunca y la ideología judicial de "lavarse las manos"!)

Toda reflexión sobre el Derecho conlleva implicaciones éticas. Es así, quiérase o no, por cuanto ella destaca tales o cuales conductas, sean solamente en el orden intelectual o también considerando aspectos materiales sociales, llevadas a cabo por los operadores jurídicos. Esas conductas pueden ser las que ya están ahí u otras que se señalan como posibles cambios. Con ello queda implicado, al menos en forma implícita, que es bueno o no tan bueno, conveniente o inconveniente, etc., que el jurista razone así.

Comparando el razonamiento jurídico realista con la fundamentación jurídica normativista resulta que, a pesar de todo, tienen en común algo fundamental: ambos caminos constituyen formas del pensamiento jurídico. ¿Por qué, y en qué, son específicamente "jurídicos" tanto el uno como la otra? Si recordamos los cuatro pasos que componen el itinerario de la fundamentación jurídica realista, vemos que en el primer "momento" son decisivas, y a partir de allí lo son también para marcarle límites a los otros tres momentos, justamente unas ideas con que nos encontramos asimismo en razonamientos normativistas: los topoi pertinentes de textos oficiales y de textos doctrinarios, llamados a colación para resolver una cuestión de derecho. La diferencia entre ambas aproximaciones no reside en la peculiaridad de basarse especialmente sobre semejantes topoi, sean unos u otros, sino en que: a) el trabajo con dichos topoi es encarado por los realistas en función de dos presupuestos [supra: $\S 4$ ] que, por el contrario, los normativistas no toman en cuenta; b) y sobre todo, los realistas no se quedan trancados en el primer momento, como los normativistas, sino que, con base en él, aquellos se preocupan por seguir adelante en el esfuerzo por arribar a la respuesta jurídica más adecuada, prosiguen la investigación jurídica completándola mediante tres momentos más que no asoman (por lo menos conscientemente) en el horizonte normativista. En cambio, el discurso normativista procede a amurallarse en una especie de "cielo" de conceptos y buscar esencialmente allí toda respuesta jurídica. El normativismo de los juristas consiste, pues, ni más ni menos que en restringir el tratamiento de las cuestiones jurídicas a 
los planteamientos propios de una Razón amputada, encerrándola dentro del primer momento. Son razonamientos truncos, ya que se dan por satisfechos con, se autoconfinan a, NO ir más allá del primer paso para responder a esas cuestiones.

Ello tiene consecuencias prácticas de primordial importancia. El juez normativista, basándose en que le basta con hurgar en ese cielo, "no levantar los ojos" de ahí, no considera necesario tomar en cuenta, para justificar la decisión jurídica por él sostenida, qué repercusiones ésta pueda tener, o no, en los hechos. Piensa más o menos así (pero, por supuesto, no lo dirá con tanta franqueza): "Lo de las consecuencias prácticas, ¡eso no me incumbe a mí! La decisión a que llego en la sentencia, y las razones en que la fundamento, nada de eso lo he decidido yo mismo, me lo impone indefectiblemente lo establecido al respecto en el dominio soberano [cielo] de las "verdades" jurídicas, del cual simplemente soy un oyente atento y servidor leal". - Así, el juez se lava las manos en cuanto a las efectos reales de sus fallos.

El normativismo es una trampa para la Razón práctica en general. Entre los juristas, esa trampa se hace "falsa conciencia" que funciona como ideología profesional típica de su gremio ${ }^{39}$. Ya lo dije, el normativismo jurídico es una forma de "lavarse las manos". Con esto quiero señalar que no se trata apenas de un error intelectual. No es simplemente una forma engañosa, por no decir mentirosa, de presentar las cosas (Superstición del Unico Significado Verdadero, Basic Legal Myth, etc.). Tampoco es una cuestión simplemente valorativa, como tantas, o sea, cierta opción ni más ni menos justificable, como tal, que otras. Se trata también, y sobre todo, de mucho más, de algo que la mayoría de los errores y la mayoría de los juicios de valor no conllevan necesariamente: es "huirle al bulto" de la responsabilidad práctica que tiene la función judicial. El normativista dice: "Yo no tengo la culpa, no tuve más remedio que resolver asi”. ¡Pero eso no es cierto! Cuando se presentan posibilidades distintas dentro del marco legal, las opciones de interpretación, no es verdad que el juez "no puede" resolver de una u otra manera, entre interpretaciones lingüísticamente viables. No, no es que "no podía": él NO QUISO resolver de manera distinta... ipero "se lava las manos"! Quiere decir que la "técnica" de fundamentación normativista implica una ética de ir-responsabilidad para los jueces, en cuanto a los efectos que para los seres de carne y hueso ocasionan las decisiones judiciales.

Por el contrario, las fundamentaciones realistas presuponen aceptar una ética de la res-ponsabilidad de los propios jueces por buena parte de las

${ }^{39}$ Para un examen más circunstanciado de esa ideología, con referencia específicamente a los triviales planteamientos de un autor que está de moda, v. Haba 2001a. 
consecuencias prácticas que acarrean sus fallos, ya que el jurista realista no tiene ambages en reconocer que a menudo el "marco" legal tolera márgenes de interpretación y que estos permiten al intérprete autorizado inclinarse ya sea por unas $u$ otras soluciones jurídicas. Ante aseveraciones tan francas se ha objetado que hacerles tomar a los jueces conciencia de tal cosa conllevaría poner en sus manos la potestad de decidir arbitrariamente. Se dice que una vez armados de semejante poder, esto provocaría que, en la práctica, ellos no titubearían en fallar incluso más allá del "marco" legal. Tampoco hay seguridad alguna, se agrega, de que esta arbitrariedad vayan a utilizarla para elegir soluciones más justas y de mayor practicidad para alcanzar valiosos fines sociales, sino que posiblemente sus decisiones serían, a menudo, todavía menos adecuadas que las resultantes de razonamientos normativistas, además de ser mucho más inseguras que estas. Así se saca la consecuencia de que, justamente desde el punto de vista práctico, lo mejor es que los jueces sigan creyendo en la ficción del Unico Significado Verdadero, como autofreno a la tentación de usar arbitrariamente su libertad. - Si tal observación fuera correcta, mal podría decirse que la fundamentación realista es más "responsable" que la normativista. Pero, ¿cómo saber quién tiene razón? Si de lo que se trata es de juzgar las consecuencias prácticas de adoptar una u otra de esas dos orientaciones, las pruebas al respecto no pueden ser de tipo apriorista y consistir simplemente en unas suposiciones. Las pruebas, para ser tales, es indispensable recabarlas de la experiencia judicial misma.

En cuanto al normativismo, las comprobaciones sobre su ajenidad a la práctica son tan frecuentes y han sido señaladas de manera tan abundante, que la evidencia cae por su peso; no veo qué más se pueda pedir para enterarse de ello. Desde luego, eso no quiere decir que todas, y seguramente ni siquiera la gran mayoría, de las sentencias normativistas han de ser, por fuerza, contraproducentes en la práctica. Muchas de ellas, posiblemente la mayoría, podrían ser refrendadas hasta por un razonamiento jurídico realista; pero este, para ser tal, tendría que fundamentarlas, cuando fuera necesario, de manera menos "trunca". El verdadero punto en discusión no es si sea posible acertar también por vías meramente normativistas, en muchos casos, sino dos cuestiones de base: i) si tales vías, el normativista, constituyen la mejor manera, en el plano intelectual, de fundamentar resoluciones prácticas de orden jurídico; y ii) si ello no abre la puerta para que en no pocos casos (aunque no sean la mayoría) se yerre, desde el punto de vista práctico, justamente por caer en déficits de racionalidad que una fundamentación realista permitiría evitar.

La verdad es que, si bien hay abundante prueba empírica de yerros imputables al normativismo de los jueces, no menos cierto es, también, que 
falta "testar" suficientemente en la práctica las alternativas de razonamiento realista para los casos señalados. Tales pruebas escasean porque, justamente, los juristas no suelen presentar sus argumentaciones de esa manera. Por lo general, los jueces no invocan fundamentos realistas, sea o no que los tomen en cuenta en su fuero íntimo, ni tampoco los abogados de las partes se atreven a plantear las cosas francamente asi (también, entre otros motivos, por temor a chocar con el normativismo de los jueces).

De todas maneras, si se examinan numerosas resoluciones judiciales cuestionables por sus consecuencias prácticas, no es difícil darse cuenta de que, en la mayoría de ellas, podría haberse acudido a una alternativa realista de fundamentación que evitase las consecuencias indeseables acarreadas por yerros imputables a estrecheces normativistas en que incurre el juez. Y el normativista debería estar en condiciones de ofrecer incluso la prueba inversa: exhibir unos fallos fundamentados realísticamente, o en todo caso una fundamentación realista presentada como alternativa en estudios de teoría jurídica, donde las consecuencias prácticas sean perjudiciales de una manera que, precisamente, se evitase razonando al modo normativista.

No se ve por qué los jueces realistas fueran a "abusar" de su libertad, que es inevitable, más de lo que en general hacen jueces normativistas. No menos unos que otros están limitados, en la práctica, por dos fuertes vallas. a) En general, los jueces se sienten sujetados por su propia conciencia profesional, moral, ideológica, etc. ¿Por qué la de los realistas habría de ser más "floja" que la de los normativistas? Y además, por si no alcanzara con esa, su propia conciencia: b) los jueces están vigilados por factores de su entorno social, tanto los institucionales como los de orden público general y múltiples "presiones" personales, todo lo cual no les permite "salirse" habitualmente del marco legal y ni siquiera elegir con total libertad dentro de él. ¿Por qué estos factores no habrían de "pesar" igualmente sobre jueces realistas?

Dado que la argumentación realista obliga a poner abiertamente "las cartas sobre la mesa", así resulta que tanto los principios - "axiomas" valorativos en posición de fines- como las referencias a la realidad social -los medios de eficacia práctica- van a quedar, de tal manera, netamente sometidos a la posibilidad de un claro control público de racionalidad, dentro y fuera del tribunal. Las fundamentaciones normativistas escapan a semejante posibilidad. Se conforman con refugiarse en su cielo dogmático, cuyas figuras son por principio no menos ajenas que inmunes a pruebas y contrapruebas de orden empírico-social. En cambio, las razones realistas pertenecen al orden de la racionalidad fáctica. Tales razones, al ser intersubjetivamente controlables, hacen así plenamente responsable a quien las presenta, mientras que las fundamentaciones normativistas se basan en unas "evidencias" 
iusmísticas. Estas últimas, por escapar a la posibilidad de ser verificadas o falsadas intersubjetivamente, hacen que el elegir entre una y otra respuesta jurídica venga a ser, al fin de cuentas, una cuestión de "gustos" doctrinarios, queda diluida la responsabilidad intelectual de quien recurre a ellas.

En síntesis.- 1) Es por demás abundante la prueba empírica de la existencia de fallos judiciales que, justamente por haber sido producidos con base en un enclaustramiento normativista del pensamiento jurídico, han tenido efectos muy contraproducentes en la práctica. 2) En cambio, no se sabe de pruebas semejantes en cuanto a que, para aquellos mismos casos u otros, una fundamentación realista lleve a consecuencias prácticas similares $\mathrm{o}$ aun peores.

Por todo lo señalado, en realidad la alternativa no está planteada entre menor libertad con jueces normativistas y mayor libertad con jueces realistas. Tan libres son, de hecho, los unos como los otros ${ }^{40}$. La gran diferencia es:

- entre fallos para el "cielo" y fallos para la "tierra";

- entre fundamentaciones truncas y fundamentaciones plenamente racionales;

- entre fundamentaciones en clave de me-lavo-las-manos-por-lo-quepase y fundamentaciones en clave de reconozco-que-elegi-yo-mismo-loque-pasará.

En definitiva, dos éticas judiciales. Una de ellas, esencialmente dogmática y escapista: normativismo. Pero enfrente queda abierta la posibilidad, metodología realista-crítica, de sacar adelante una ética de la plena RESPONSABILIDAD intelectual y social del juez, como sujeto moral de sus propios fallos.

${ }^{40}$ Téngase muy presente el hecho que señalan las palabras de Frank recogidas en el encabezamiento de este artículo, tomadas de Law. (o.c supra: nota 14): 169, nota 8. 


\section{Otros estudios del autor}

(La lista çconsigna solo trabajos vinculados estrechamente con lo desarrollado en el presente artículo)

(1972): Esquemas metodológicos en la interpretación del derecho escrito, Universidad Central de Venezuela/Facultad de Derecho (Cuaderno de Filosofia del Derecho $\mathrm{N}^{\mathrm{o}}$ 9), Caracas.

(1980): Prólogo; en J. E. Romero Pérez, La Sociología del Derecho en Max Weber (2 ed.), pp. i-xxxiv, Oficina de Publicaciones de la Universidad de Costa Rica.

(1990): “Racionalidad y método para el derecho: ¿es eso posible?", Doxa, Nos 7 y 8. Una versión corregida y algo ampliada apareció en Revista de Ciencias Jurídicas (Univ. de C.R.), N ${ }^{\text {os }} 66$ (mayo-agosto 1990) y 67 (setiembre-diciembre 1990); de esta versión hubo también un pequeño tiraje independiente.

(1991): "Sciences du droit - quelle "science"?", Archives de Philosophie du Droit, t. 36 , pp. 165-187.

(1993): “Kirchmann sabía menos... ipero vio mejor! “, Doxa-14. [Versión revisada: en 1999b]

(1995): "Sobre el Derecho como "técnica" o "tecnología"”, Doxa-17/18. [También en 1999b]

(1996a): “ Lógica formal y Derecho”, Enciclopedia Jurídica Omeba-Apéndice VII, pp. 625-632.

(1996b): "Ciencias del derecho. La controversia de paradigmas en la Teoría del Derecho contemporánea", Ibíd., pp. 107-145. [Versión revisada: en 1999b.]

(1996c): “Teoría del Derecho y metodologismo”, Ibíd., pp. 1017-1029.

(1996d): "Una discusión: ¿Quiénes son los “irracionalistas” en la Teoría del Derecho?”, Doxa-19. [Vers. rev. y ampl.: "Racionalidad e irracionalidad en el Derecho", en 1999b.]

(1996e): "Standortbestimmung zeitgenössischer Rechtstheorie - Rawls, Dworkin, Habermas und andere Mitglieder der "Heiligen (Rede-)Familie"", Rechtstheorie, t. 27 (vol. 3: Habermas-Sonderheft), Berlín.

(1997): "Variantes del pensamiento escapista en una moderna "Santa Familia": sobre Rawls, Habermas, etc. (Acerca de la concepción "misionera" para las ciencias sociales)", Sistema 137 (marzo 1997), Madrid.

(1998): “Teorización constructivista como "forma de vida"”; Doxa-21 (vol. I).

(1999a): "Precomprensiones, racionalidad y métodos, en las resoluciones judiciales."; Doxa-22.

(1999b): AA.VV. (Haba et al.), J. F. Palomino Manchego (Dir.), Discusión sobre el carácter anticientífico del Derecho, Grijley, Lima.

(2000): “Semiótica ilusionista y semiótica desencantadora”, Doxa-23.

(2001a): "Rehabilitación del no-saber en la actual Teoría del Derecho: El bluff Dworkin", Doxa-24.

(2001b): "Normativismo y realismo como opciones del juez (De la Razón práctica amputada a la racionalidad jurídica integral)"; en AA.VV. (Coordinadores: L. I. Zerpa y J. M. Delgado), Curso de Capacitación Judicial sobre Razonamiento Judicial y Argumentación Jurídica, Tribunal Supremo de Justicia de Venezuela. 
[Una versión revisada de ese trabajo forma parte de una obra colectiva que publicará próximamente la Corte Suprema de Justicia de Costa Rica.]

(2001c): AA.VV., E. P. Haba (Dir.), Axiología jurídica fundamental. Bases de valoración en el discurso jurídico (Materiales para discernir en forma analítico-realista las claves retóricas de esos discursos), Textos destinados a la Cátedra de Filosofía del Derecho, San José (C.R.), xiii-376 p.

(2002): Id., Elementos básicos de Axiología. Epistemología del discurso valorativo práctico: cuestiones generales (Materiales para discernir condiciones de racionalidad en esos discursos), Textos destinados a la Cátedra de Filosofía del Derecho, San José (C.R), xix-371 p.

(2003a) "En torno a las formas de discursear sobre el talismán "derechos humanos" (Un compendio de observaciones poco edificantes respecto a maneras de decir mucho y no decir nada)"; en R. Carrión Wam (editor, compilador), Derechos humanos/Direitos humanos, Universidad de Carabobo, en prensa.

(2003b): El espejismo de la interpretación literal, Escuela Judicial de Costa Rica, en prensa. 
$\triangle \quad$ DOXA 25 (2002) 